\title{
Echocardiographic restenosis after successful balloon dilatation of the mitral valve with the Inoue balloon: experience of a United Kingdom
}

\section{centre}

\author{
M R Thomas, M J Monaghan, L K Michalis, D E Jewitt
}

\begin{abstract}
Objectives-(a) To assess the echocardiographic incidence of restenosis after successful balloon dilatation of the mitral valve at a mid-term follow up of one year among a population of predominantly United Kingdom patients. (b) To identify any factors, assessed before or during dilatation, which may predict the development of restenosis.
\end{abstract}

Design-Successful dilatation of the mitral valve was defined as an increase in mitral valve area of $>\mathbf{2 5 \%}$ and a final valve area of at least $1.5 \mathrm{~cm}^{2}$. Echocardiographic restenosis was defined at follow up as a loss of $\mathbf{5 0 \%}$ of initial gain and a valve area of less than $1.5 \mathrm{~cm}^{2}$. Mitral valve area was assessed by transthoracic echocardiography before, during, 48 hours after, and one year after successful balloon dilatation of the mitral valve. Echo score before dilatation (an assessment of valvar and subvalvar calcification, thickening, and mobility), age, rhythm, echocardiographic mitral valve area before and after dilatation, left atrial pressure before and after dilatation, and end diastolic mitral valve gradient before and after dilatation were compared in those patients with and without echocardiographic restenosis at one year.

Setting-A regional cardiothoracic centre in the United Kingdom that performs 20-30 balloon dilatations of mitral valves each year.

Patients-39 patients, with symptomatic dominant mitral stenosis, who had undergone successful balloon dilatation of the mitral valve, and in whom echocardiographic assessment of mitral valve area was available at one year. $92 \%$ of patients were citizens of the United Kingdom.

Interventions-Balloon dilatation of the mitral valve by the Inoue technique.

Main outcome measures-Mitral valve area and patient symptom class (New York Heart Association) one year after successful dilatation of the mitral valve.

Results-The incidence of echocardiographic restenosis was eight of 39 patients $(21 \%)$. Of the eight patients with restenosis four underwent mitral valve replacement, two had repeat dilatation of the mitral valve, and two remained on medical treatment. With univariant analysis, factors associated with resteno- sis were increased age, higher echo score before dilatation, and a lower mitral valve area immediately after the operation. The only independent risk factor for restenosis, shown by multivariant analysis, was a high echo score before dilatation. There was no significant fall in mitral valve area at one year in those patients without restenosis. Most (28/31) of these patients had echocardiographic evidence of splitting of at least one commissure after dilatation compared with only two of eight patients who developed restenosis. Of 10 patients with an echo score before dilatation $\geqslant 10$ only two had an initially successful operation and no restenosis at one year.

Conclusions-The echocardiographic incidence of restenosis after dilatation of the mitral valve by the Inoue technique in patients of the United Kingdom is $21 \%$. The principal factor associated with restenosis is a high echo score before dilatation. Increases in mitral valve area are maintained in those patients without restenosis and it is likely that the mechanism of initial increase in valve area is different in the two groups, being commissural splitting in those patients who do not get restenosis and valve stretching in those that do. In patients with an echo score $\geqslant 10$ dilatation of the mitral valve should be considered only as a palliative procedure.

(Br Heart f 1993;69:418-423)

Balloon dilatation of the mitral valve is now established as an alternative to surgery in a selected group of patients with dominant mitral stenosis. ${ }^{1-3}$ The ideal candidate for dilatation of the mitral valve is a young patient, with a pliable valve, commissural fusion, and little valvar or subvalvar calcification or thickening. Increase in mitral valve area is thought to be achieved by splitting of the medial or lateral commissures during balloon inflation. ${ }^{45}$ With the virtual eradication of rheumatic fever in the United Kingdom the ideal patient for dilatation of the mitral valve is rarely seen in this country. Patients are often elderly with at least some mitral valve calcification.

Therefore the aim of the present study was to see if increases in mitral valve area were maintained over a mid-term follow up of one year in a group of patients predominantly 
from the United Kingdom who had undergone successful balloon dilatation of the mitral valve by the Inoue balloon.

\section{Patients and methods}

For the purposes of the study successful dilatation of the mitral valve was defined as an increase in mitral valve area of $>25 \%$ and a final valve area $\geqslant 1.5 \mathrm{~cm}^{2}$; without significant mitral regurgitation, systemic emboli, or left to right shunt, whereas echocardiographic restenosis was defined at follow up as a loss of $50 \%$ of the initial gain and a valve area $<1.5$ $\mathrm{cm}^{2}{ }^{1}$

\section{PATIENTS}

Balloon dilatation of the mitral valve with the Inoue balloon was attempted in 52 patients between 1989 and 1991. Primary success was achieved in 49 of 52 patients (94\%). Of the three patients who had an initial suboptimal result, one developed severe mitral regurgitation requiring urgent mitral valve replacement and two failed to have a final valve area of $1.5 \mathrm{~cm}^{2}$. One year follow up data were not available in 10 patients resulting in a final study population of 39 patients.

There were 24 women and 15 men with a mean age of 57 (range 22-77) years. Twenty nine patients were in atrial fibrillation and 10 in sinus rhythm. Thirty six of the 39 patients (92\%) were from the United Kingdom. Three patients had previously undergone a closed surgical mitral valvotomy.

\section{METHODS}

\section{Balloon dilatation of the mitral valve}

In all cases dilatation of the mitral valve was performed by the Inoue technique as first described by Inoue et al in $1984 .^{7}$ With the right femoral approach and a transeptal puncture a safety $\mathrm{J}$ guide wire was positioned within the left atrium. The septostomy was subsequently enlarged with a $14 \mathrm{~F}$ vessel dilator. The Inoue balloon was passed across the atrial septum before being flow guided to the left ventricle. Segmental inflation of the balloon was then performed within the mitral valve.

During the procedure echocardiographic planimetery and colour flow Doppler, left atrial pressure, and end diastolic mitral valve gradient were used to assess the results of serial balloon inflations on mitral valve area and mitral regurgitation.

Maximum balloon size was gauged by the patient's height (as recommended by the manufacturers) and ranged from 25 to 29 $\mathrm{mm}$.

\section{Echocardiography}

Transthoracic echocardiography was performed with a Hewlett-Packard $\mathbf{7 7 0 2 0}$ Phased Array Scanner and a $2 \cdot 5-\mathrm{MHz}$ transducer. Echocardiography was performed before, during, 48 hours after, and one year after dilatation. Transoesophageal echocardiography was also carried out, to exclude left atrial thrombus, in the last 42 of the 52 patients in whom dilatation was performed with the Inoue balloon.

Assessment of mitral valve areas was predominantly by direct planimetry (35 of 39 patients), with the parasternal short axis view at the level of the leaflet tips, as it is widely recognised that this method gives the most reproducible estimate of mitral valve area immediately after dilatation of the mitral valve. ${ }^{8}$ In the four patients in whom reliable planimetry of the mitral valve could not be performed, the valve area was assessed by the Doppler pressure half time method before dilatation and at one year follow up. Immediately after dilatation in these four patients the Gorlin formula was used to calculate mitral valve area. These two methods have been shown to correlate well with planimetered valve area at these times before and after dilatation. ${ }^{9}$

Before dilatation echocardiography was used to assign each patient an echo score of suitability for dilatation of the mitral valve as first described by Wilkins et al in $1988 .{ }^{10}$ With this method a score of zero to four is given for each of valve calcification, subvalvar thickening, leaflet mobility, and valve thickening. It has previously been shown that patients with a score of eight or less have better immediate and short-term outcomes after dilatation than do those with higher scores. ${ }^{10}$ Higher echo scores are associated with more rigid calcified valves.

\section{STATISTICAL ANALYSIS}

Results are displayed as the mean (SD). Echo results before and after dilatation were compared with a paired $t$ test. Results within subgroups were compared with a two sample $t$ test. In an attempt to identify factors associated with restenosis, univariant and stepwise multiple regression analysis of nine variables were performed in the 39 patients in whom echocardiographic data were available at one year. The variables analysed were age, rhythm, mitral valve area before and 48 hours after dilatation, left atrial pressure before and immediately after dilatation, end diastolic mitral valve gradient before and immediately after dilatation, and echo score before dilatation. A p value $<0.05$ was considered significant.

\section{Results}

MITRAL VALVE AREA

Figure 1 shows changes in mitral valve area for the whole group before dilatation, 48 hours after dilatation, and at one year. Before dilatation mean mitrial valve area was 0.99 $(0.21) \mathrm{cm}^{2}$. There was a highly significant increase in valve area 48 hours after mitral dilatation $\left(1.84(0.33) \mathrm{cm}^{2}, \mathrm{p}<0.0001\right)$. At one year there had been a significant fall in mitral valve area for the group as a whole $\left(1.67(0.42) \mathrm{cm}^{2}, \mathrm{p}<0.01\right)$. The individual changes in valve area show that most patients' increases in valve area were maintained but in some patients there was a noticeable fall in valve area. 


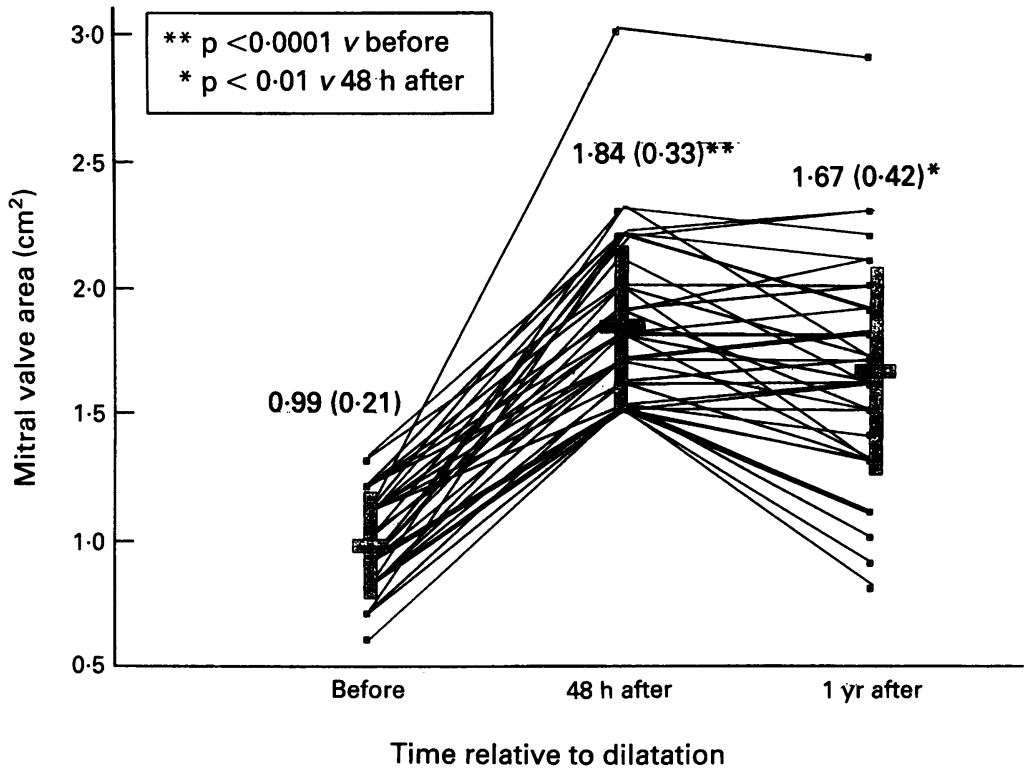

Figure 1 Individual changes in mitral valve area 48 hours and one year after balloon dilatation of the mitral valve for the whole group $(n=39)$. Values are mean $(S D)$.

Echocardiographic restenosis occurred in eight of 39 patients (21\%) (fig 2). Mean mitral valve area before dilatation was similar in those patients who went on to develop echocardiographic restenosis and in those who did not $\left(1.0(0.29) \mathrm{cm}^{2} v 0.99(0.19)\right.$ $\left.\mathrm{cm}^{2}, \mathrm{NS}\right)$. Forty eight hours after dilatation, however, mean mitral valve area was significantly lower in the restenotic compared with the non-restenotic group $\left(1.6(0.18) \mathrm{cm}^{2} v\right.$ $\left.1.9(0.33) \mathrm{cm}^{2}, \mathrm{p}<0.01\right)$. In those patients without restenosis there was no significant fall in valve area at one year $\left(1.9(0.33) \mathrm{cm}^{2} v 1.8\right.$ $\left.(0.32) \mathrm{cm}^{2}, \mathrm{NS}\right)$ suggesting that the restenosis process may be an all or nothing phenomenon. Planimetry could not be reliably performed in two patients from the nonrestenotic group and another two patients from the restenotic group.

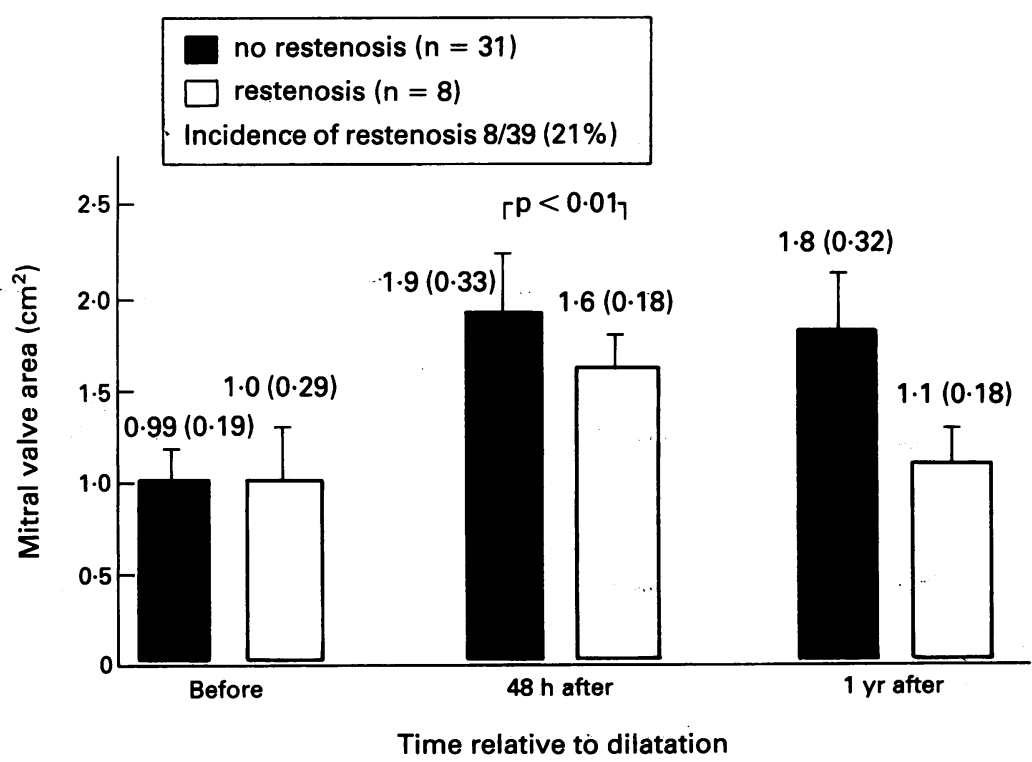

Figure 2 Serial changes in mitral valve area in patients with and without echocardiographic restenosis. Values are mean (SD).
FACTORS ASSOCIATED WITH

ECHOCARDIOGRAPHIC RESTENOSIS

In an attempt to identify factors that may be associated with echocardiographic restenosis, factors such as age, rhythm, echo score before dilatation, left atrial pressure, and end diastolic mitral valve gradient were compared in the restenotic and non-restenotic groups (table). Univariant analysis showed that patients who went on to develop restenosis were older (65 (10) years $v 55$ (17) years, $\mathrm{p}<0.05)$, had a higher echo score before dilatation $(9.9(1.6) v 7.0(1.7), \mathrm{p}<0.001)$, and had a lower valve area 48 hours after dilatation $\left(1.6(0.18) \mathrm{cm}^{2} v 1.9(0.33) \mathrm{cm}^{2}\right.$, $\mathrm{p}<0.01)$. Multivariant analysis indicated that the only independent risk factor for the development of restenosis was a higher echo score before dilatation $(p<0.01)$. Atrial fibrillation was present in a similar proportion in each group (23/31 $v 6 / 8$, NS).

Invasive values used in the assessment of mitral stenosis such as left atrial pressure and end diastolic mitral valve gradient, whether measured before or after dilatation of the mitral valve, did not predict those patients who went on to develop echocardiographic restenosis.

\section{CHANGES IN FUNCTIONAL CAPACITY}

Changes in the functional capacity of patients were assessed by the New York Heart Association (NYHA) functional grading system. ${ }^{11}$ Figure 3 shows changes in functional class for the whole group, and specifically in the restenotic subgroup.

For the whole group before dilatation most patients were in functional class 2 or 3 with six patients in class 4 (fig $3(\mathrm{~A})$ ). Dilatation of the mitral valve resulted in an improvement of two functional classes in 16 patients and one functional class in 21 patients. Only two patients had no improvement in symptoms after dilatation. The symptomatic improvement was generally maintained at one year: $85 \%$ (33 of 39) of patients were in class 1 or class 2.

Figure 3(B) shows changes in functional class within the restenotic group. Seven of the eight patients had an initial improvement of at least one functional class after dilatation of the mitral valve and were in class 1 or 2 after the operation. At follow up, however, five of

Factors associated with restenosis

\begin{tabular}{|c|c|c|}
\hline & $\begin{array}{l}\text { No restenosis } \\
(n=31)\end{array}$ & Restenosis $(n=8)$ \\
\hline $\begin{array}{l}\text { Age (yr) } \\
\text { Atrial fibrillation }\end{array}$ & $\begin{array}{l}55(17) \\
23\end{array}$ & $65(10)^{\star}$ \\
\hline 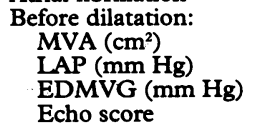 & $\begin{array}{l}0.99(0 \cdot 19) \\
25 \cdot 0(8 \cdot 0) \\
13 \cdot 6(6 \cdot 1) \\
7 \cdot 0(1 \cdot 7)\end{array}$ & $\begin{array}{l}1 \cdot 0(0 \cdot 29) \\
22 \cdot 4(8 \cdot 0) \\
12 \cdot 3(8 \cdot 5) \\
9 \cdot 9(1 \cdot 6)^{\star \star \star} \dagger\end{array}$ \\
\hline $\begin{array}{l}\text { After dilatation }(48 \mathrm{~h}) \text { : } \\
\text { MVA }\left(\mathrm{cm}^{2}\right) \\
\text { LAP }\left(\mathrm{mm} \mathrm{Hg}^{\mathrm{H}}\right) \\
\text { EDMVG }(\mathrm{mm} \mathrm{Hg})\end{array}$ & $\begin{array}{c}1.9(0.33) \\
15 \cdot 3(5 \cdot 2) \\
3.6(3 \cdot 2)\end{array}$ & $\begin{array}{l}1 \cdot 6(0 \cdot 18)^{\star \star} \\
14 \cdot 3(5 \cdot 5) \\
.5(5 \cdot 0)\end{array}$ \\
\hline
\end{tabular}

${ }^{\star} \mathrm{p}<0.05 ;{ }^{\star \star} \mathrm{p}<0.01 ;{ }^{\star \star \star} \mathrm{p}<0.001$, univariant analysis. tp $<0.01$, multivariant analysis.

MVA, mitral valve area; LAP, left atrial pressure; EDMVG, end diastolic mitral valve gradient. 
A

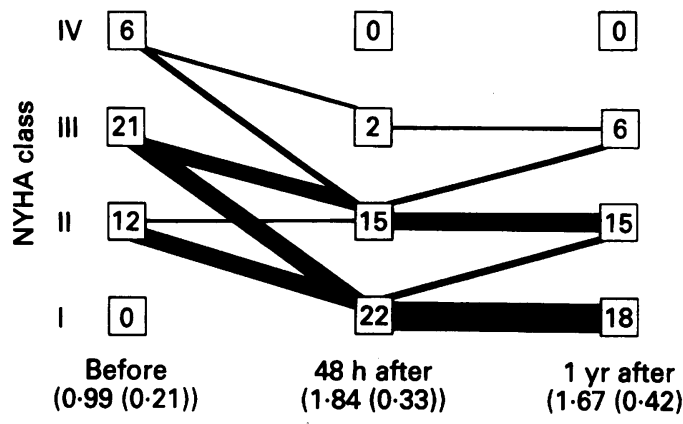

Time relative to dilatation (mean (SD) mitral valve area)
B

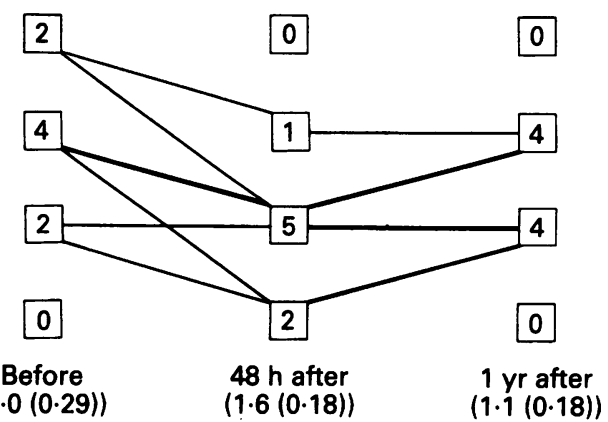

Time relative to dilatation (mean (SD) mitral valve area)

Figure 3 (A) Changes in NYHA functional class for the group as a whole. 37/39 patients had an improvement of at least one functional class after dilatation and $85 \%$ of patients were in functional class 1 or 2 at one year. (B) In the subgroup with echocardiographic restenosis at one year seven of eight patients had an initial improvement of at least 1 functional class, but by one year five of eight patients had noted a deterioration in symptoms (the thickness of lines relates to the number of patients moving between any two groups. See text for treatment of this group).

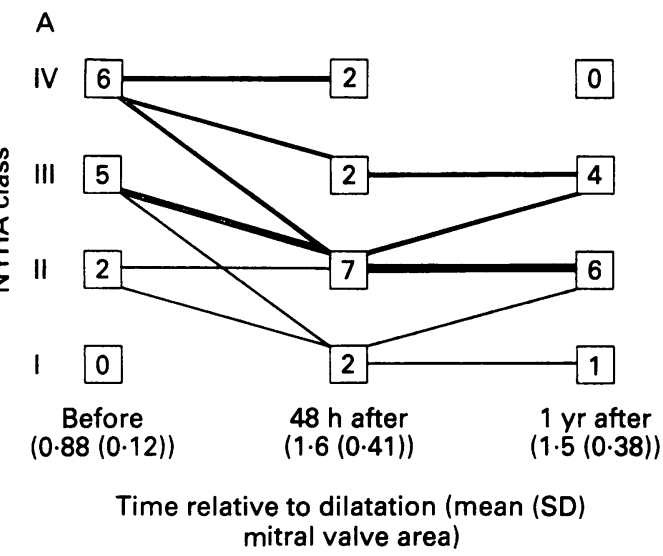

B

Figure 4 (A) Changes in NYHA functional class for patients $\geqslant 70$ years of age. Two patients had an initial suboptimal result with a valve area of $<1.5 \mathrm{~cm}^{2}$. Ten patients had an initial improvement of at least 1 functional class but three noted that symptoms deteriorated by one year. 54\% (7/13) remained in class 1 or 2 at one year. (B) Of 10 patients with an echo score before dilatation of $\geqslant 10$, three had an initial suboptimal result, and five developed echocardiographic restenosis. Therefore, only two had sustained benefit from the procedure (the thickness of lines relates to number of patients moving between any two groups.)

eight patients had noted a deterioration in clinical symptoms. Of the four patients in class 3 at one year two went on to mitral valve replacement, and two had a repeat dilatation. Of the four patients in class 2 at follow up, two had mitral valve replacement and two were sufficiently well to be kept on medical treatment.

Figure 4 shows subgroup analysis of the changes in functional class in elderly patients and in those with a high echo score. We have attempted dilatation of the mitral valve in 13 patients over 70 years of age. Two patients had a suboptimal result, failing to have a final valve area of $1.5 \mathrm{~cm}^{2}$ Of the remaining 11 patients 10 had an initial improvement of at least 1 NYHA functional class. At follow up three patients had echocardiographic restenosis, but $54 \%$ (seven of 13 ) of this elderly group were in functional class 1 or 2 at one year (fig $4(A)$ ). Figure $4(B)$ shows results for patients with a high echo score before dilatation. We have attempted dilatation of the mitral valve in 10 patients with an echo score of $\geqslant 10$. Three patients had an initial suboptimal result, two failed to have a final valve area of $1.5 \mathrm{~cm}^{2}$ and one developed acute mitral regurgitation requiring urgent mitral valve replacement. Of the remaining seven patients six had an initial improvement in functional class. At one year five patients had echocardiographic restenosis resulting in only $20 \%$ (two of 10 ) of these patients having sustained benefit from the operation (fig $4(B)$ ).

\section{Discussion}

Initial results of percutaneous balloon dilatation of the mitral valve compare favourably with those from surgical valvotomy or valve replacement. ${ }^{1213}$ Mitral valve morphology, however, has been shown to have an important influence on the outcome of attempted balloon dilatation and this procedure may be less useful in older patients with more rigid calcified mitral valves. ${ }^{10}$

Mitral valve morphology at the time of dilatation of the mitral valve will vary consid- 
erably throughout the world, because of the different ages at which patients present, and this is likely to have a profound influence on the primary success rate of the procedure and on subsequent restenosis. Younger patients present with pliable valves, commissural fusion, and little valvar or subvalvar calcification and thickening, making them ideal patients for dilatation. In previous reports of balloon dilatation of the mitral valve the mean age of patients has varied from as low as 22 years in India ${ }^{14}$ to as old as 55 years in America ${ }^{15}$ with intermediate age groups being reported in Saudia Arabia (26 years), ${ }^{16}$ China (32 years), ${ }^{17}$ France (43 years), ${ }^{1}$ and Canada (51 years). ${ }^{18}$ Reported primary success rates vary from $100 \%$ in younger patients ${ }^{14}$ to $69 \%$ in the more elderly American population. ${ }^{19}$ Reports on rates of restenosis vary similarly. Al Zaibag et al reported no restenosis at one year in a group of young patients (mean age 26 years) who had undergone successful dilatation of the mitral valve. ${ }^{16}$ By contrast, Palacios et al reported a rate of restenosis of $19 \%$ (13 of 69 ) in an older group (mean age 55 years) of American patients. ${ }^{19}$ The mean age of the patients in our study was 57 years, and is one of the oldest in any dilatation series to date. The elderly United Kingdom patient frequently has a rigid, thickened, and often a calcified mitral valve at the time of dilatation of the mitral valve, and the rate of primary success and restenosis should be similar to the American experience. There have been no previous reports of the incidence of primary success or restenosis from a United Kingdom centre.

Our results show that dilatation of the valve should be considered as a viable option for treatment of United Kingdom patients with symptomatic dominant mitral stenosis, with a primary success rate of $94 \%$ and $95 \%$ of patients being in NYHA class 1 or 2 after the operation. The incidence of echocardiographic restenosis is however considerable, in this series being $21 \%$ (eight of 39). Univariant analysis indicated that those patients who went on to develop restenosis were older, had a higher echo score before dilatation, and had a lower mitral valve area after the operation than those patients who maintained their mitral valve area at one year. Despite this last risk factor, it cannot be recommended that increased balloon sizes should be used if, after use of the maximum recommended balloon size, a successful dilatation has been achieved but an ideal valve area (from our data about $1.9 \mathrm{~cm}^{2}$ ) has not been reached. These patients will often be those with mitral calcification and some subvalvar thickening and are therefore at most risk of developing significant mitral regurgitation..$^{20}$

Should dilatation of the mitral valve therefore be attempted in elderly patients or those with high echo scores? Figure 4 shows the results of our experience in performing dilatation of the mitral valve in the elderly and in those with a high echo score before dilatation. Our results shows that dilatation is a valuable interventional option in elderly patients in the United Kingdom with mitral stenosis. Ten out of 13 patients had an initial improvement of at least one NYHA functional class after the operation and $54 \%$ (seven of 13) of this elderly group were in class 1 or 2 at one year. The results for patients with a high echo score before dilatation are less encouraging. Six of our 10 patients in this subgroup did have an initial improvement in functional class. At one year, however, only $20 \%$ (two of 10) of these patients had a sustained benefit from the operation (fig 4(B)).

The mechanism for the increase in valve area after dilatation of the mitral valve is generally thought to be commissural splitting. ${ }^{45}$ Some authors have described valve stretching as contributing to the increase in valve area. ${ }^{21}$ There was echocardiographic evidence of splitting of at least one commissure in 28 of 31 patients who did not develop restenosis whereas commissural splitting was only convincingly found in two of eight patients who went on to develop echocardiographic restenosis. These data suggest that the mechanism for the increase in valve area may have been different in the two groups, in one being due to commissural splitting and in the other due to valve stretching. Restenosis may not therefore be the best terminology in the group who failed to maintain their increases in valve area, elastic recoil being a more accurate description of the pathological process.

It should be noted that of the five patients who eventually underwent mitral valve surgery in this series (four after the development of restenosis and one who developed acute mitral regurgitation) all had a mitral valve replacement because the surgeon did not consider that the valve morphology was suitable for open or closed mitral valvotomy. This again would seem to reflect the unfavourable valve morphology at the time of presentation. Comparisons of the success, morbidity, and mortality of percutaneous balloon dilatation of the mitral valve with the surgical treatment of mitral stenosis within the United Kingdom should therefore be with a mixed group of surgical patients undergoing mitral valve replacement along with open or closed mitral valvotomy.

In conclusion balloon dilatation of the mitral valve should be considered a valuable technique in the treatment of dominant mitral stenosis in the United Kingdom, with a $94 \%$ primary success rate and $84 \%$ of patients being in NYHA class 1 or 2 at one year. Echocardiographic restenosis occurs in $21 \%$ of patients at one year. A significant proportion of these patients, however, will remain well and do not require further intervention. Despite the association of increasing age with echocardiographic restenosis, over $50 \%$ of patients $>70$ years old will be in NYHA class 1 or 2 at one year making dilatation of the mitral valve an interventional option in elderly United Kingdom patients with mitral stenosis. Invasive haemodynamic valves such as left atrial pressure or end diastolic mitral valve gradient, whether measured 
before or after dilatation, do not predict the occurrence of echocardiographic restenosis. Of the factors associated with echocardiographic restenosis the most important seems to be a high echo score before operation: patients with an echo score of $\geqslant 10$ have particularly disappointing results with an increased incidence of initial suboptimal results and often only short-term increases in mitral valve area. Balloon dilatation of the mitral valve should, therefore, only be considered as a palliative procedure in this subgroup of patients.

1 Vahanian A, Michel PL, Cormier B, et al. Results of percutaneous mitral commissurotomy in 200 patients. $\mathrm{Am}$ 7 Cardiol 1989;63:847-52.

2 Block PC, Palacios IF. Aortic and mitral balloon valvuloplasty: The United States experience. In: Topol EJ ed. Saunders, 1990:831-48.

3 Inoue K, Hing JS. Percutaneous transvenous mitral commissurotomy (PTMC): the far east experience. In:
Topol EJ ed. Texbook of interventional cardiology. Philadelphia: W B Saunders, 1990:887-99.

4 McKay RG, Lock JE, Safian RD, et al. Balloon dilation on mitral stenosis in adult patients: postmortem and percutaneous mitral

5 Reid CL, McKay CR, Chandraratna PAN, Kawanishi DT, Rahimtoola SH. Mechanisms of increase in mitral valve area and influence of anatomic features in doubleballoon, catheter balloon valvuloplasty in adults with rheumatic mitral stenosis: a Doppler and two-dimensional echocardiographic study. Circulation 1987;76: 628-36.

6 Abascal VM, Wilkins GT, O'Shea JP, et al. Prediction of successful outcome in 130 patients undergoing percuta-
neous balloon mitral valvotomy. Circulation 1990;82: 448-56.

7 Inoue K, Owaki T, Nakamura T, Kitamura F, Miyamoto N. Clinical application of transvenous mitral commissurotomy by a new balloon catheter. $\Im$ Thorac Cardiovasc Surotomy 1984;87:394-402.

8 Wilkins GT, Thomas JD, Abascal VM, et al. Failure of the Doppler half-time to accurately demonstrate change in mitral valve area following percutaneous mitral valvotomy [abstract]. $\mathcal{F} \mathrm{Am}$ Coll Cardiol 1987;9:218A

9 Abascal VM, Wilkins GT, Choong CY, et al. Echocardiographic evaluation of mitral valve structure and function in patients followed for at least 6 months afte percutaneous balloon mitral valvuloplasty. $₹ \mathrm{Am}$ Coll Cardiol 1988;12:606-15.

10 Wilkins GT, Weyman AE, Abascal VM, Block PC Palacios IF. Percutaneous balloon dilatation of the mitral valve: an analysis of echocardiographic variable related to outcome and the mechanism of dilatation. $B$ Heart $\mathcal{f}$ 1988;60:299-308.

11 Criteria Committee New York Heart Association. Nomenclature and criteria for diagnosis of diseases of the heart and great vessels. 7 th ed. Boston: Little Brown Co, 1973:286.

12 Mullin EM, Glancy DL, Higgs LM, Epstein E, Morrow AG. Current results of operation for mitral stenosisclinical and haemodynamic assessment in 124 consequative patients treated by closed commissurotomy, quative patients treated by closed commissurotomy,
open commissurotomy, or valve replacement. open commissurotomy,

13 Turi ZT, Reyes VP, Raju S, et al. Percutaneous balloon versus surgical closed commissurotomy for mitral stenosis. A prospective, randomized trial. Circulation 1991;83: 1179-85.

14 Natarajan D, Sharma VP, Sharma SC. Percutaneous mitral valvotomy by Inoue catheter in young patients with mitral stenosis. Am Heart $\mathcal{F}$ 1992;123:541-3.

15 The National Heart, Lung and Blood Institute Balloon Valvuloplasty Registry Participants. Multicentre experience with balloon mitral commissurotomy. Circulation 1992;85:448-61.

16 Al Zaibag M, Ribeiro PA, Kasab SA, et al. One-year follow-up after percutaneous double balloon mitral valvolow-up after percutaneous double ball

17 Chen $C$, Lo $Z$, Huang $Z$, Inoue $K$, Cheng TO Percutaneous transseptal balloon mitral valvuloplasty: the Chinese experience in 30 patients. Am Heart $f$ 1988;115:937-47.

8 Cequier A, Bonan R, Serra A, et al. Left-to-right atria shunting after percutaneous mitral valvuloplasty. Circulation 1990;81:1190-7.

19 Palacios IF, Block PC, Wilkins GT, Weyman AE. Followup of patients undergoing percutaneous mitral balloon valvotomy: analysis of factors determining restenosis. Circulation 1989;79:573-9.

20 Casale PN, Marwick TH, Stewart WJ, Grigera F Whitlow PL. Mitral calcification is the best predictor of symptomatic mitral regurgitation requiring valve symptomatic mitral regurgitation requiring valve replacement following balloon mitral

21 Nabel E, Bergin PJ, Kirsh MM. Morphological analysis of balloon mitral valvuloplasty: intraoperative results [abstract]. $\mathcal{F}$ Am Coll Cardiol 1990;15:97A. 